\title{
Innovative Bio-based Poly(Lactic Acid)/Poly(Alkylene Furanoate)s Fiber Blends for Sustainable Textile Applications
}

\author{
Davide Perin $^{1}$ (D) . Daniele Rigotti ${ }^{1} \cdot$ Giulia Fredi $^{1} \cdot$ George Z. Papageorgiou ${ }^{2} \cdot$ Dimitrios N. Bikiaris $^{3} \cdot$ Andrea Dorigato $^{1}$
}

Accepted: 27 April 2021 / Published online: 7 May 2021

(c) The Author(s) 2021

\begin{abstract}
This work aims at producing and investigating, for the first time, the microstructural and thermo-mechanical properties of fibers constituted by poly(lactic acid) (PLA)/poly(alkylene furanoate)s (PAFs) blends for textile applications. Two different PAFs have been investigated, i.e., poly(octylene furanoate) (P8F) and poly(dodecylene furanoate) (P12F), which have been blended with PLA in different concentrations and spun through a lab-made wet spinning device. The microstructural investigation of the fiber cross-section evidenced domains of PAFs homogeneously dispersed within the PLA matrix. The immiscibility of the produced blends was also suggested by the fact that the glass transition temperature of PLA was unaffected by the presence of PAF. The thermal stability of PLA was not substantially influenced by the PAF content, whereas the water absorption tendency decreased with an increase in P12F fraction. The mechanical properties of PLA/P8F blends decreased with the P8F amount, while for PLA/P12F fiber blends the stiffness and the strength were approximatively constant by increasing the $\mathrm{P} 12 \mathrm{~F}$ content. The drawing process, performed at $70{ }^{\circ} \mathrm{C}$ and with two different draw ratios, brought an interesting increase in the mechanical properties of PLA fibers upon P12F introduction. These promising results constitute the basis for future research on these innovative bio-based fibers.
\end{abstract}

Keywords Poly(lactic acid) $\cdot$ Furanoates $\cdot$ Fibers $\cdot$ Drawing $\cdot$ Mechanical properties

\section{Introduction}

It is well known that the problem of plastic pollution has recently attracted increasing scientific and popular concerns [1]. The public awareness of the environmental impact of fossil fuel-based polymers has steeply increased in the last years and has forced industries and governments to develop initiatives to move toward a more sustainable use of plastics [2]. Improving the sustainability of plastic products is thus a big challenge for human society, and an increasing number of bio-based matrices have been recently developed and

Davide Perin

davide.perin-1@unitn.it

1 Department of Industrial Engineering and INSTM Research Unit, University of Trento, Via Sommarive 9, 38123 Trento, Italy

2 Department of Chemistry, University of Ioannina, P.O. Box 1186, 45110 Ioannina, Greece

3 Chemistry Department, Laboratory of Polymer Chemistry and Technology, Aristotle University of Thessaloniki, 54124 Thessaloniki, Greece industrialized [3-5]. Biopolymers, which are polymers that are biodegradable and/or produced starting from renewable resources, are a promising option for reducing the environmental impact of plastics [6]. In the last decades bio-derived, recyclable and compostable plastics have been extensively investigated, and bioplastics like poly(lactic acid) (PLA) [7], polyhydroxyalkanoates (PHAs) [8], and thermoplastic starch [9] were introduced on the market. In particular, PLA is a linear aliphatic poly ( $\alpha$-ester) [10], synthesized by the ionic polymerization of lactide [4], which is formed by the dehydration-condensation of two lactic acid molecules. Since the lactic acid molecules possess two different optical forms, labeled as L-lactic acid and D-lactic acid, lactide presents three different isomeric forms: L-lactide, D-lactide, and D-L-lactide (also known as meso lactide) depending on how the building blocks are linked together [11, 12]. From the ionic polymerization of L-lactide and D-lactide, two different PLA are obtained, known as poly(L-lactic acid) (PLLA) and poly(D-lactic acid) (PDLA), respectively [13, 14]. Commercially speaking, the most widely used PLA is composed of PLLA with a small content of PDLA [15]. On the other hand, from the polymerization of meso lactide, 
the amorphous polymer known as poly (L, D-lactic acid) (PDLLA) can be obtained [16, 17]. PLA is a biopolymer exhibiting high tensile modulus (approximately $3 \mathrm{GPa}$ ), good mechanical strength (higher than $60 \mathrm{MPa}$ ), high workability, and higher transparency in comparison to other biopolymers, showing also a compostable and recyclable nature [7]. For all these reasons it has been intensively studied as a possible substitute for traditional matrices in composite materials and in packaging applications [18-20].

In recent years, a new family of biopolymers containing a furan ring structure derived from 2,5-furandicarboxylic acid (FDCA) has attracted the attention of researchers to produce homopolymers [21, 22] or copolymers [23]. However, due to the lack of an economical and viable industrial process for producing the precursors, furan-based polymers are not yet widely used [24]. Among the different types of furan polymers, poly(alkylene furanoate)s (PAF)s are the most widely investigated, since they possess interesting mechanical and thermal performance and significantly high barrier properties [25]. The most important PAF is probably poly(ethylene 2,5 furandicarboxylate) (PEF), the bioderived counterpart of polyethylene terephthalate (PET) [26]. PEF presents improved gas barrier properties in comparison to PET, good thermal and mechanical resistance, but it shows a brittle behavior at room temperature. Thanks to these properties, PEF could be a potential substitute for PET only if its brittleness will be significantly reduced. Besides PEF, different PAFs homopolyesters based on aliphatic diols with a higher number of carbon atoms have been recently synthesized, like poly(propylene 2,5-furandicarboxylate) (PPF) [27], poly(butylene 2,5-furandicarboxylate) (PBF) [28], poly(hexamethylene 2,5-furandicarboxylate) (PHF) [29], poly(octylene 2,5-furandicarboxylate) (POF or P8F) [30], poly (decylene 2,5-furandicarboxylate) (PDeF) $[31,32]$ and poly(dodecylene 2,5-furandicarboxylate) (PDoF or P12F) [33]. An increase in the number of carbon atoms of the diol leads to a decrease of the thermo-mechanical properties, like the elastic modulus, the glass transition temperature $\left(T_{g}\right)$ and the melting temperature $\left(T_{m}\right)$ [34]. On the other hand, by increasing the alkyl chain length the resulting polymers will exhibit a more ductile behavior and they could be thus applied for packaging applications [35].

Therefore, blending bio-based plastics already present on the market with innovative biopolymers possessing tailor-made properties could represent a new opportunity to completely exploit their potential [36]. A polymer blend is a physical or mechanical mixture in which at least two polymers are combined, to produce a new material having different physical properties with respect to its constituents. Generally speaking, polymer blends can be broadly divided into three categories. In immiscible or heterogeneous polymer blends the constituents are present in separate phases. In a miscible or homogeneous polymer blend, the mixture of two or more polymers results in a single-phase structure $[37,38]$. In a compatible polymer blend, the constituents are present in separate phases but the blend exhibits macroscopically uniform properties due to the strong interaction between the components of the polymer alloy. Although the majority of polymers are generally non-miscible, blending is a common technique to modify and/or improve the properties of polymer matrices, usually in a more cost-effective way in comparison to the synthesis of new plastics. Several works in the literature report the blending of PLA with different biopolymers or petroleum-based polymers, such as poly(e-caprolactone) (PCL) [39], poly(propylene) (PP) [40], thermoplastic starch [41], poly (3-hydroxybutyrate) (PHB) $[42,43]$ and poly(butylene 2,5-furan dicarboxylate) (PBF) [44].

Some studies have been also recently conducted on PAFs based blends. Papageorgiou et al. [45] performed a comprehensive investigation on poly(alkylene furanoate)/ poly(alkylene terephthalate) (PAT) blends and concluded that in many cases PAF/PAT blends were immiscible. PEF and PPF showed dynamic homogeneity and miscibility, while only PPF/PBF blends seemed to be partially miscible. As reported in the work of Poulopoulou et al. [46], also PEF/ PBF mixtures were immiscible. Another paper concerning PLA/PBF blends has been performed by Long et al. [44]. Even these blends were immiscible, they possessed interesting optical properties. In another work of Long et al. [47], PLA/PBF blends with a PBF content of $5 \mathrm{wt} \%$ showed remarkable mechanical properties, with elongation at break values about 18 times higher than that of neat PLA and without substantially affecting the stiffness and the yield resistance. Moreover, PBF introduction was responsible for a remarkable increase in the gas barrier properties. In conclusion, Fredi et al. [48] studied the preparation of PLA/PAF blends in the form of cast films.

In the last years, the improvement of the sustainability of polymeric fibers represented a challenge both from an academic and industrial point of view. Fibers are either natural or man-made products that, by definition, forms the basic element of fabrics and other products such as vegetable tissues, mineral substances or textile products [49]. Nowadays fibers are widely applied in many fields, e.g. textiles, fabrics and composite materials. Due to the considerable employment of synthetic fibers, a more sustainable fiber production must be performed, involving also the use of bio-based polymers [50]. One of the most widely applied processes to improve the mechanical properties and the dimensional stability of the fibers is drawing. This process is often performed at elevated temperatures (i.e. between the $T_{g}$ and the $T_{m}$ of the matrix), in order to promote the mobility of the macromolecules and their alignment along the drawing direction. Generally speaking, the drawing process results 
in an increased polymer chain density and an improved strength in comparison to the as-spun fibers [51].

On the basis of these considerations, this study reports the production through wet spinning process of PLA/P8F and PLA/P12F blends in the form of fibers which, to the best of the authors' knowledge, has never been investigated before in the open literature. The main goal of the work is to develop novel fully bio-based PLA/PAF fibers for textile applications with improved toughness and lower water absorption tendency compared to neat PLA, thereby tacking the main shortcomings of PLA. A complete characterization of the as-spun fibers was performed, in order to highlight the effect of the PAF type and content on the microstructural, thermal, and mechanical properties of the resulting blends. Fibers with optimized formulation were then drawn at different draw ratios, in order to detect the influence of the chain alignment and of the P12F addition on their physicomechanical properties.

\section{Materials and Methods}

\section{Materials}

The PLA used in this work was an Ingeo ${ }^{\circledR}$ biopolymer 4032D (density $=1.24 \mathrm{~g} / \mathrm{cm}^{3}$, MFI at $210{ }^{\circ} \mathrm{C}$ and 2.16 $\mathrm{kg}=7 \mathrm{~g} / 10 \mathrm{~min}$ ) produced by NatureWorks LLC (Minnetonka, United States) in pellets form. Two different PAFs have been used for the production of fiber blends. The first is poly (1,8-octylene 2,5-furandicarboxylate) $(\mathrm{P} 8 \mathrm{~F})$. It is a biopolymer derived from a two-steps polycondensation of 2,5-dimethylfuran-dicarboxylate (DMFD) and 1,8-octamethylenediol, and it has a number average molecular weight $\left(\mathrm{M}_{\mathrm{n}}\right)$ of approximately $36,500 \mathrm{Da}$, a polydispersity index (D) equal to 1.8 , a $T_{g}$ of $-5{ }^{\circ} \mathrm{C}$, and a $T_{m}$ of approximately 157 ${ }^{\circ} \mathrm{C}$ [30]. Moreover, it presents a very fast crystallization rate and also a cold crystallization at a temperature of approximately $38{ }^{\circ} \mathrm{C}$ [30]. The second is poly (1,12-dodecylene 2,5-furandicarboxylate) (P12F). It is a polymer derived from a two-steps polycondensation of DMFD and 1,12-dodecamethylene glycol, and as reported in the work of Papageorgiou et al. [33] it shows a $T_{g}$ of $-5{ }^{\circ} \mathrm{C}$ and a $T_{m}$ of 111 ${ }^{\circ} \mathrm{C}$. Both PAFs were synthesized in form of small slabs in the Department of Chemistry of the Aristotle University of Thessaloniki (Greece). Chloroform (HPLC grade), ethanol (purity 99.9\%) and methanol (purity 99.9\%) were purchased by Carlo Erba Reagents Srl (Milano, Italy). All the materials were used as received.

\section{Samples Preparation}

\section{Fiber Spinning Process}

As briefly explained in the introduction, fiber blends were prepared through a wet spinning process. Neat PLA, PLA/ P8F, and PLA/P12F mixtures were dissolved in chloroform by the fact that this solvent has been reported to dissolve both PLA and furan-based polyesters with a relatively long alkyl chain [45, 52]. The polymer concentration was $0.75 \mathrm{~g}$ over $5 \mathrm{~mL}$ of solvent, and the resulting solution was magnetically stirred at $40{ }^{\circ} \mathrm{C}$ for approximately $3 \mathrm{~h}$. The obtained solutions were then mildly ultrasonicated for $10 \mathrm{~min}$ in a Labsonic LBS1 bath (Falc Instruments Srl, Bergamo, Italy), in order to remove small air bubbles that were formed during the stirring process, and then transferred in a glass syringe with a capacity of $10 \mathrm{~mL}$. The spinning process was performed with a lab-made device shown in Fig. 1. The glass syringe containing the polymer solution was fixed on a Harvard apparatus Model 11 Single Syringe 55-1199 (Harvard apparatus Inc., Holliston, USA) and connected with a 18 gauge needle, which was subsequently sealed to the nonsolvent bath. After some preliminary trials, the spinning velocity has been set at $0.007 \mathrm{~mL} / \mathrm{min}$, while the speed of the take-up rollers was fixed at $60 \mathrm{rpm}$. The solution passed then through a non-solvent bath, with the aim of removing the solvent and produce thus continuous fibers. The non-solvent

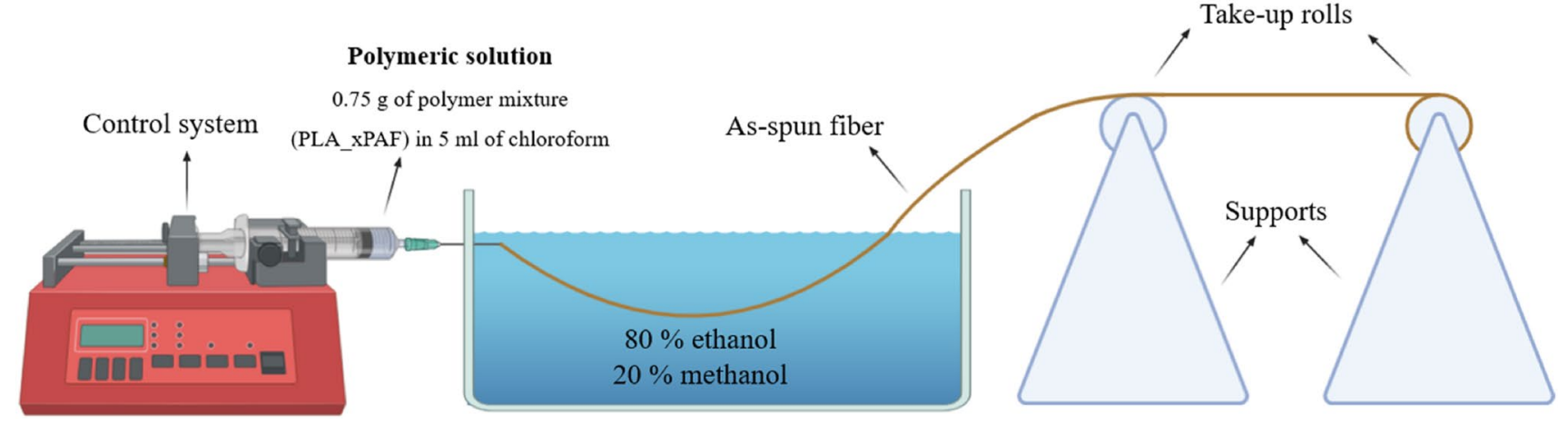

Fig. 1 Schematization of the wet-spinning process employed for the production of the fibers 
bath contained $80 \mathrm{vol} \%$ of ethanol and $20 \mathrm{vol} \%$ of methanol, since both these solvents were able to induce PLA crystallization [53]. The obtained fibers were collected with take up rollers and left $24 \mathrm{~h}$ in the air, in order to allow complete solvent evaporation. The fibers were then stored in a desiccator with dry silica salts until their use.

Two different groups of fiber blends have been produced. The first was a PLA/P8F mixture with P8F weight concentrations from 5 to $30 \mathrm{wt} \%$, while the second was a PLA/P12F blend with P12F contents from 5 to $30 \mathrm{wt} \%$. Each sample was labeled as PLA_xPAF, where $\mathrm{x}$ represents the weight content of PAF in the polymer alloy. Neat PLA fibers were also spun for comparison. An attempt was made to spun neat $\mathrm{P} 8 \mathrm{~F}$ and P12F fibers, but it was successful only with the neat P12F ones. Table 1 reports the list of the produced fibers, together with the nominal weight fraction of PAF.

\section{Fiber Drawing}

To improve the mechanical properties of the obtained fibers and to investigate the effect of the macromolecular orientation, a drawing process has been performed both on neat PLA and on the PLA_20P12F fiber blends. This composition was selected on the basis of the results of the mechanical characterization performed on the as-spun fibers (see Paragraph 3.1). The drawing process has been performed using an Instron ${ }^{\circledR} 5969$ electromechanical testing machine (ITW Test \& Measurement and Equipment, Norwood, USA), equipped with a $100 \mathrm{~N}$ load cell and an Instron ${ }^{\circledR}$ 3119-409 thermostatic chamber. Fibers having a gauge length of $50 \mathrm{~mm}$ were deformed at a fixed strain rate and under a constant temperature. In the work of Hyon et al.

Table 1 List of prepared as-spun fibers

\begin{tabular}{lll}
\hline PAF content $[w t \%]$ & PLA/P8F & PLA/P12F \\
\hline 0 & PLA & \\
5 & PLA_5P8F & PLA_5P12F \\
10 & PLA_10P8F & PLA_10P12F \\
20 & PLA_20P8F & PLA_20P12F \\
30 & PLA_30P8F & PLA_30P12F \\
100 & - & P12F \\
\hline
\end{tabular}

[54], the drawing of PLA fibers was performed at $160^{\circ} \mathrm{C}$ and the highest strength and modulus were obtained when the asspun fibers were drawn with a DR of 13. On the other hand, in the study of Hilborn et al. [55], as-spun fibers were subjected to a drawing process at $90{ }^{\circ} \mathrm{C}$ with DR ranging from 2 to 10 , followed by a heat setting at $120^{\circ} \mathrm{C}$. In this work, a drawing temperature of $70^{\circ} \mathrm{C}$ was utilized. This temperature was selected as it lays in the temperature window between the $T_{g}$ of PLA (approx. $55^{\circ} \mathrm{C}$ ) and the melting point of P12F, which starts at $80^{\circ} \mathrm{C}$ (see DSC tests in Fig. 5). It is also important to underline that at $70^{\circ} \mathrm{C}$ also $\mathrm{P} 12 \mathrm{~F}$ is above its $T_{g}$ (i.e. $-5{ }^{\circ} \mathrm{C}$, as reported by Papageorgiou et al. [33]). In these conditions, the motion of the polymeric chains in both the blend constituents is favoured. Considering the deformation level of the fibers during the drawing process, it was possible to determine the DR, which is usually defined as the ratio between the collection $\left(R_{\mathrm{c}}\right)$ and the feeding $\left(R_{\mathrm{f}}\right)$ rate, as reported in Eq. (1) [56].

$D R=\frac{R_{C}}{R_{F}}=\left(\frac{D_{i}}{D_{f}}\right)^{2}$

where the $D_{\mathrm{i}}$ represents the initial fiber diameter, and $D_{\mathrm{f}}$ represents the diameter of the fiber after the drawing process. In the works of Hyon et al. [54] and Hilborn et al. [55], high DR levels have been achieved, and the mechanical properties of the drawn fibers were thus noticeable enhanced. At the drawing temperature selected in the present work, it was not possible to reach these DR values, as the fibers were fractured before reaching the desired deformation. Therefore, in this paper, the total deformation of the fibers was set at 50\% or $150 \%$, applied at a drawing speed of $50 \mathrm{~mm} / \mathrm{min}$. These deformations respectively correspond to nominal DR levels of 1.7 and 2.7. Table 2 reports the list of the drawn fibers and the parameters involved in the drawing process.

\section{Experimental Techniques}

Light microscope (LM) micrographs of the produced fiber blends were obtained with a CH-9435 Heerbrugg optical microscope (Heerbrugg, Switzerland). According to the experimental procedure developed by Fredi et al. [57], LM images of the fiber cross-section were obtained by winding
Table 2 List of the prepared drawn fibers and parameters involved in the drawing process

\begin{tabular}{llllll}
\hline Sample & Nominal DR & $\begin{array}{l}\text { Total deforma- } \\
\text { tion [\%] }\end{array}$ & $\begin{array}{l}\text { Drawing speed } \\
{[\mathrm{mm} / \mathrm{min}]}\end{array}$ & $\begin{array}{l}\text { P12F content } \\
{[\mathrm{wt} \%]}\end{array}$ & $\begin{array}{l}\text { draw- } \\
\text { ing T } \\
{\left[{ }^{\circ} \mathrm{C}\right]}\end{array}$ \\
\hline PLA_D1.7 & 1.7 & 50 & 50 & 0 & 70 \\
PLA_20P12F_D1.7 & & & & 20 & 70 \\
PLA_D2.7 & 2.7 & 150 & 50 & 0 & 20 \\
PLA_20P12F_D2.7 & & & &
\end{tabular}


the fibers to a poly(methyl methacrylate) (PMMA) parallelepiped and subsequently embedding the entire parallelepiped in cylindrical epoxy beads. The obtained epoxy beads were subsequently grinded with a sequence of abrasive papers of decreasing roughness $(500,800,1200,4000)$ and then polished with the help of polishing clothes with a roughness of $3 \mu \mathrm{m}$ and $1 \mu \mathrm{m}$, in order to obtain smooth cross-section surfaces. Field Emission Scanning Electron Microscopy (FESEM) micrographs of the lateral surfaces of the fiber blends were obtained with a Zeiss Supra 60 (Carl Zeiss AG, Oberkochen, Germany) microscope after Pt-Pd sputtering, under an acceleration potential of $2.5 \mathrm{kV}$.

Differential scanning calorimetry (DSC) was performed with a Mettler DSC 30 calorimeter (Mettler Toledo, Inc., Columbus, USA) at $10{ }^{\circ} \mathrm{C} / \mathrm{min}$ and between -50 and 250 ${ }^{\circ} \mathrm{C}$, under a nitrogen flow of $100 \mathrm{~mL} / \mathrm{min}$. Specimens of approximately $6 \mathrm{mg}$ were sealed in aluminum crucibles and subjected to a first heating scan, followed by a cooling scan, and a second heating scan. This analysis enabled the determination of the $T_{\mathrm{g}}$, the $T_{\mathrm{m}}$, the cold crystallization temperatures $\left(T_{\mathrm{cc}}\right)$, and the enthalpy values $\left(\Delta H_{\mathrm{m}}, \Delta H_{\mathrm{cc}}\right)$ of the blend constituents. The transition temperatures were measured with a precision of $0.02{ }^{\circ} \mathrm{C}$, while the relative enthalpy values with a precision of $1 \%$ and an accuracy of $4 \%$. Equation (2) shows how to evaluate the crystalline content $(\chi)$ of the two polymer phases in the blends, expressed in [\%].

$\chi=\frac{\Delta H_{m}-\Delta H_{c c}}{\Delta H_{m}^{*} \cdot \omega} \cdot 100$

where $\Delta H_{c c}$ is the enthalpy of cold crystallization of PLA (or PAF) in the blend, $\Delta H_{m}$ is the enthalpy of melting of PLA (or PAF) in the blend, $\Delta H_{m}^{*}$ is the enthalpy of melting of fully crystalline PLA (or PAF), while $\omega$ is the weight fraction of PLA (or PAF) in the blend. $\Delta H_{m}^{*} P L A$ value was equal to $93.7 \mathrm{~J} / \mathrm{g}$ [58], while the evaluation of the crystalline content of P8F was not possible since the theoretical enthalpy of melting of P8F $\left(\Delta H_{m_{\_} P 8 F}^{*}\right)$ has not been found in literature. $\Delta H_{m_{-} P 12 F}^{*}$ value was equal to $158.0 \mathrm{~J} / \mathrm{g}$ [33].
Thermogravimetric analysis (TGA) was carried out with a Mettler TG50IR thermobalance (Mettler Toledo Inc., Columbus, USA). Specimens of approximately $4 \mathrm{mg}$ were tested at a heating rate of $10{ }^{\circ} \mathrm{C} / \mathrm{min}$ up to $700{ }^{\circ} \mathrm{C}$, under a nitrogen flow of $100 \mathrm{~mL} / \mathrm{min}$. These tests allowed the establishment of the water loss $\left(m_{\mathrm{H}_{2} \mathrm{O}}\right)$, of the degradation temperature $\left(T_{d}\right)$, determined as the peak of the mass loss derivative (DTG) curve and representing the temperature at which the maximum degradation rate is achieved, and of the residual mass at $700{ }^{\circ} \mathrm{C}\left(m_{700}\right)$.

Quasi-static tensile tests were performed at room temperature by using an Instron ${ }^{\circledR} 5969$ tensile testing machine (ITW Test \& Measurement and Equipment, Norwood, USA) equipped with a $100 \mathrm{~N}$ load cell. Fiber specimens, having a gauge length of $50 \mathrm{~mm}$, were mounted on paper frame supports and tested at a crosshead speed of $1 \mathrm{~mm} / \mathrm{min}$. At least six specimens were tested for each composition. In this way, the elastic modulus $(E)$, the stress at yield $\left(\sigma_{y}\right)$ and the failure properties of the fibers $\left(\sigma_{b}, \varepsilon_{b}\right)$ were determined.

\section{Results and Discussions}

\section{Characterization of the As-Spun Fibers}

Figure 2a-c show the cross-sections of the as-spun fiber blends obtained through light microscopy. It is possible to observe that all the fibers possess an elliptical cross-section without the presence of air bubbles. The scratches present on the fiber cross-section are caused by the grinding procedure. The non-circular cross-section of the as-spun fibers may be caused by the deformation imparted by the take-up rolls on the fibers emerging from the non-solvent bath, that still have solvent residues and are thus easily deformable. However, further studies are necessary to completely understand the mechanism behind this particular shape of the produced fibers.

The diameter of the fibers was measured from the LM images through the software ImageJ® (National Institutes of
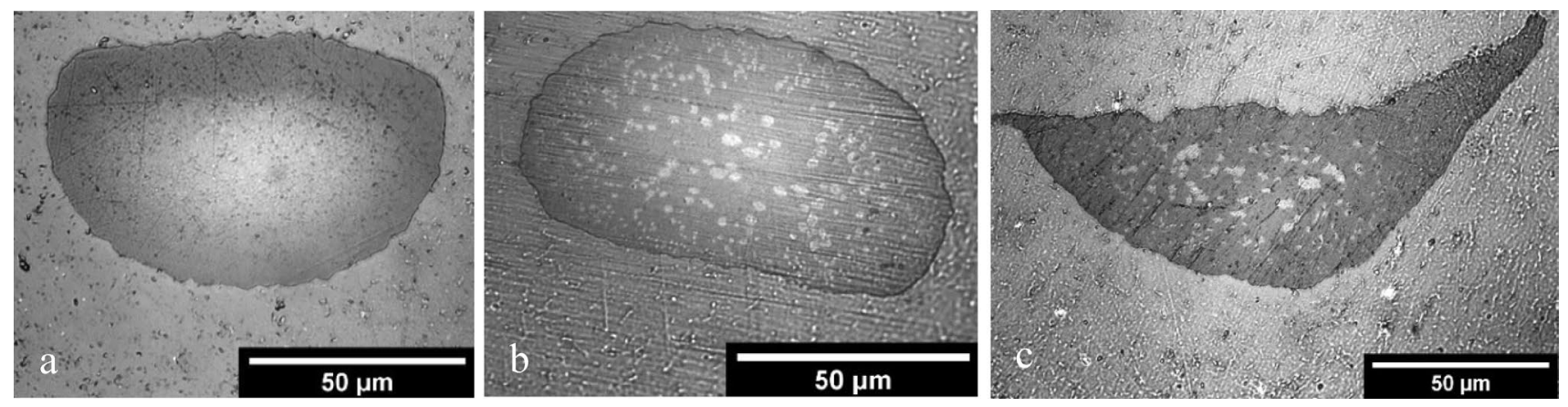

Fig. 2 Cross-section of the as-spun fiber blends obtained through light microscopy: a PLA, b PLA_20P8F, c PLA_20P12F samples 
Health campus, Bethesda, USA). Neat PLA fibers are characterized by a mean diameter of $83 \pm 10 \mu \mathrm{m}$, PLA_20P8F fibers have a mean size of $60 \pm 7 \mu \mathrm{m}$, while the diameter of PLA_20P12F fibers is $89 \pm 12 \mu \mathrm{m}$. Therefore, in both blends, the presence of PAF does not vary in a dramatic way the mean diameter of the spun fibers. Moreover, PAF domains homogeneously distributed within the PLA matrix can be detected. P8F domains in the center of the PLA matrix are characterized by a mean dimension of $3.6 \pm 1.2$ $\mu \mathrm{m}$ (Fig. 2b), while P12F domains in the center of the PLA matrix have a mean size of $3.0 \pm 0.9 \mu \mathrm{m}$ (Fig. 2c). From these micrographs, it is possible to infer that the produced fiber blends are immiscible. Furthermore, all PAF domains are mainly concentrated in the center of the fibers and their dimension decreases with the distance from the center of the fiber. A possible explanation is that both PAFs has a lower affinity to chloroform in comparison to, since PLA can be easily dissolved in chloroform, while only long alkyl chain PAFs can be dissolved in it [48]. Thus, during the first stage of the spinning process, the lateral surface of the fiber will be composed of PLA since it is more prone to coagulation in comparison to PAF and therefore PAF domains tend to aggregate in the chloroform-rich region (i.e. the center) of the fibers by the fact that they are less soluble in comparison to PLA. Furthermore, PAF domains tend to be concentrated in the center of the fiber by the fact that they act as filler inside the PLA matrix, and therefore, as reported in literature, the fillers in an extrusion process tend to be concentrated in the center of the fiber rather than in the outer surface $[59,60]$.

Figure $3 \mathrm{a}-\mathrm{c}$ report FESEM micrographs of the lateral surfaces of neat PLA, PLA_30P8F, and PLA_30P12F fiber blends. The lateral surface of PLA fiber is smooth and does not present evident defects, while both PLA_30P8F and PLA_30P12F fibers show higher surface roughness together with small defects. Even from these micrographs, the elliptical cross-section of the fibers can be detected. A similar morphology for the PLA fibers has been reported also in the research of Hilborn et al. [55]. However, at a general level, it can be concluded that the produced fibers possess a rather good surface quality, and therefore they can be utilized for the subsequent characterization activities.

Figure 4 shows the DSC thermograms of as received P8F, neat PLA, and PLA_xP8F fiber blends $(x=5-30 \mathrm{wt} \%)$, while the most important results are listed in Table 3. P8F exhibits an endothermic melting peak at $143.8^{\circ} \mathrm{C}$, while the $T_{g}$ can not be detected but it should be approximately $-5^{\circ} \mathrm{C}$, as reported in a previous paper by Bikiaris and colleagues on the thermal behavior of P8F [30]. PLA shows an endothermic melting peak at $166.2{ }^{\circ} \mathrm{C}$ and a $T_{g}$ of $54.1^{\circ} \mathrm{C}$. It is interesting to observe that the $T_{g}$ of PLA is unaltered by the presence of P8F, which confirms that PLA and P8F phases are immiscible. Another experimental evidence of the immiscibility of the blend resides in the well distinct melting phenomena of the two constituents. In Fig. $4 \mathrm{~b}$ it is possible to observe the thermograms of the second heating scan. In comparison to the first heating stage, the peak related to the crystallization process of PLA is slightly decreased as the content of P8F increases. It is quite interesting to notice that the melting event related to the P8F phase, in the second heating scan, is characterized by a small shoulder at lower temperature. This shoulder might be related to the melting of a fraction of P8F characterized by a lower molecular weight. In the first heating scan (Fig. 4a) there is a small cold crystallization peak for the PLA phase, and the crystallinity content is about $27.2 \%$, while in the second heating scan the cold crystallization peak is present, and its intensity is similar to that of the melting event. In conclusion, during the spinning process, the PLA within the blends is able to crystallize, while when the thermal history of the material is deleted upon a heating stage, PLA manifests a cold crystallization process leading to lower crystallization degrees in comparison to those calculated during the first heating scan, regardless of the presence of $\mathrm{P} 8 \mathrm{~F}$.

Figure 5a, $\mathrm{b}$ show DSC thermograms of as received P12F, of neat PLA and P12F fibers, and their relative PLA_xP12F
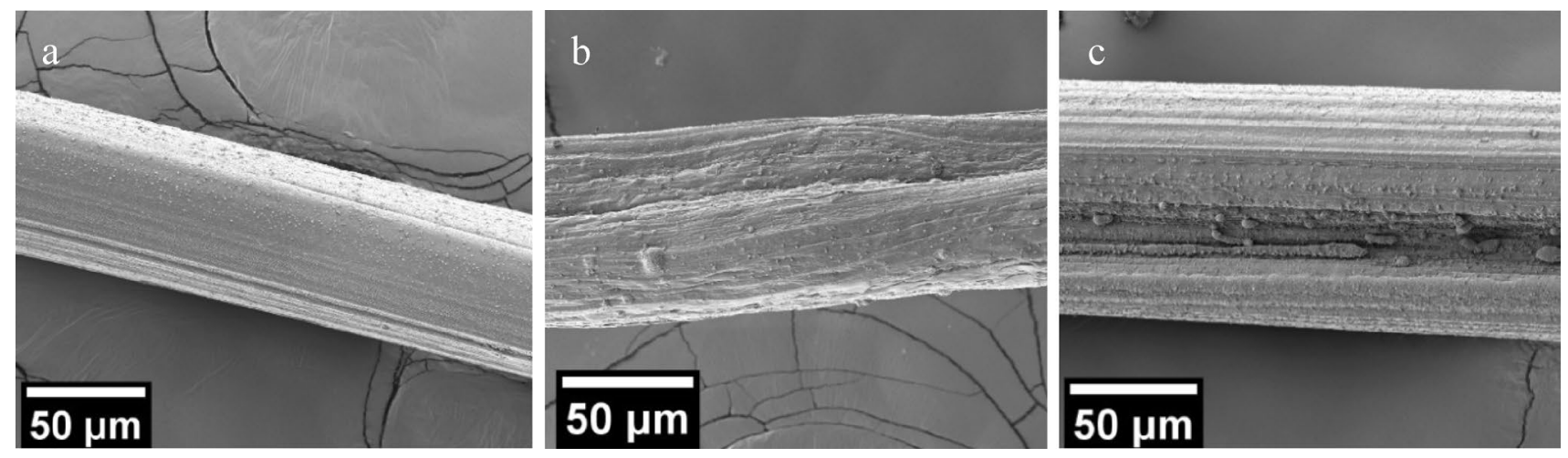

Fig. 3 FESEM micrographs of the lateral surface of as-spun fibers: a PLA, b PLA_30P8F, c PLA_30P12F 


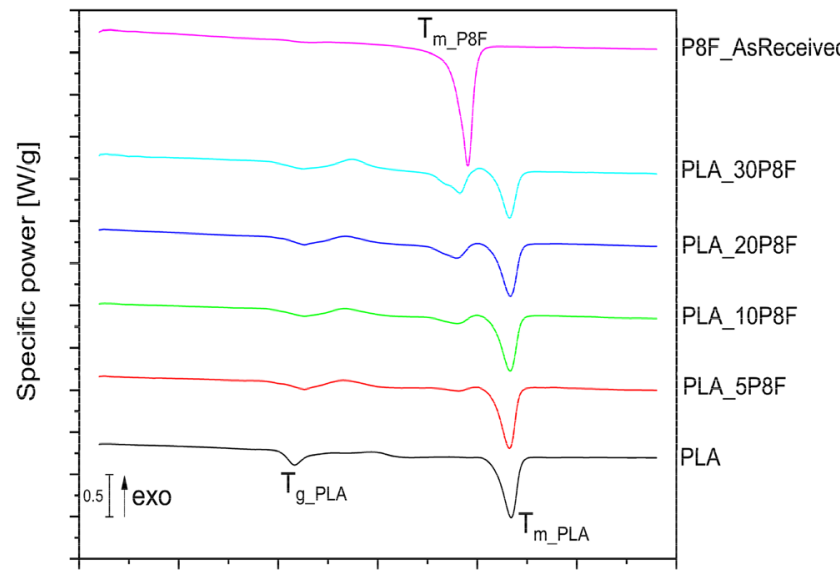

(a)

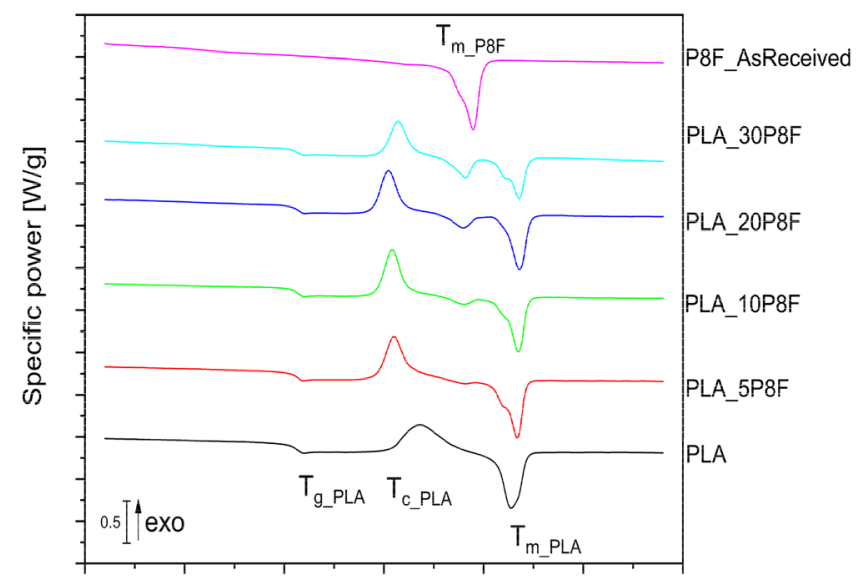

(b)

Fig. 4 DSC thermograms of P8F as received, PLA fiber, and PLA_xP8F fiber blends ( $x=5-30$ wt $\%$ ). a First heating scan, $\mathbf{b}$ second heating scan

Table 3 Results of DSC tests on PLA_xP8F fiber blends ( $\mathrm{x}=5-30 \mathrm{wt} \%)$

\begin{tabular}{|c|c|c|c|c|c|c|c|c|}
\hline Sample & $\mathrm{T}_{\mathrm{g} \text { PLA }}\left[{ }^{\circ} \mathrm{C}\right]$ & $\mathrm{T}_{\mathrm{m} \text { PLA }}\left[{ }^{\circ} \mathrm{C}\right]$ & $\Delta \mathrm{H}_{\mathrm{m} \text { PLA }}[\mathrm{J} / \mathrm{g}]$ & $\mathrm{T}_{\mathrm{mP8F}}\left[{ }^{\circ} \mathrm{C}\right]$ & $\Delta \mathrm{H}_{\mathrm{m} \mathrm{P8F}}[\mathrm{J} / \mathrm{g}]$ & $\mathrm{T}_{\mathrm{cc} \text { PLA }}\left[{ }^{\circ} \mathrm{C}\right]$ & $\Delta \mathrm{H}_{\mathrm{cc} \text { PLA }}[\mathrm{J} / \mathrm{g}]$ & $\chi_{\text {PLA }}[\%]$ \\
\hline \multicolumn{9}{|l|}{ First heating scan } \\
\hline PLA & 54.1 & 166.2 & 37.6 & - & - & 96.5 & 12.0 & 27.2 \\
\hline PLA_5P8F & 57.1 & 165.5 & 38.3 & 140.3 & 2.5 & 82.5 & 9.7 & 32.1 \\
\hline PLA_10P8F & 55.4 & 157.4 & 35.5 & 139.9 & 8.2 & 83.1 & 8.9 & 31.5 \\
\hline PLA_20P8F & 58.4 & 165.9 & 34.3 & 138.7 & 15.5 & 83.8 & 8.3 & 34.7 \\
\hline PLA_30P8F & 56.5 & 165.2 & 29.8 & 140.5 & 24.2 & 87.2 & 10.8 & 29.0 \\
\hline P8F_As Received & - & - & - & 143.8 & 80.9 & - & - & - \\
\hline \multicolumn{9}{|l|}{ Second heating scan } \\
\hline PLA & 56.1 & 163.1 & 44.0 & - & - & 118.1 & 39.9 & 4.4 \\
\hline PLA_5P8F & 56.5 & 166.2 & 34.9 & 140.3 & 2.2 & 105.1 & 32.5 & 2.7 \\
\hline PLA_10P8F & 57.3 & 166.8 & 32.7 & 139.3 & 4.2 & 104.3 & 32.4 & 0.4 \\
\hline PLA_20P8F & 56.4 & 167.0 & 32.1 & 139.4 & 8.2 & 102.5 & 31.8 & 0.4 \\
\hline PLA_30P8F & 56.2 & 166.8 & 25.9 & 140.1 & 11.2 & 106.8 & 25.7 & 0.3 \\
\hline P8F_As Received & - & - & - & 143.9 & 60.7 & - & - & - \\
\hline
\end{tabular}

$T_{g_{-} P L A}$ glass transition temperature of PLA; $T_{m_{-} P L A}$ melting temperature of PLA; $\triangle H_{m_{-} P L A}$ melting enthalpy of PLA; $T_{m_{-} P 8 F}$ melting temperature of P8F; $\Delta H_{m_{-} P 8 F}$ melting enthalpy of P8F; $T_{c c_{-} P L A}$ cold crystallization temperature of PLA; $\Delta H_{c c_{-} P L A}$ cold crystallization enthalpy of PLA; $\chi_{P L A}$ crystallinity content of PLA

fiber blends ( $\mathrm{x}=5-30 \mathrm{wt} \%$ ), while the most important results are summarized in Table 4. P12F exhibits an endothermic melting peak at $105.3^{\circ} \mathrm{C}$, while the $T_{g}$ can not be detected but it should be approximately $-5^{\circ} \mathrm{C}$, as previously shown by Papageorgiou et al. [33]. Moreover, it is interesting to notice that the thermograms of as received $\mathrm{P} 12 \mathrm{~F}$ and $\mathrm{P} 12 \mathrm{~F}$ fibers are quite similar, and this means that the wet spinning process performed did not alter the thermal properties of P12F. As in the case of PLA/P8F fiber blends, it can be observed that the $T_{g}$ of PLA is unaltered by the presence of $\mathrm{P} 12 \mathrm{~F}$, confirming thus that the produced fiber blends are immiscible. In the first heating scan (Fig. 5a) there is a small cold crystallization peak of PLA and the crystallinity content is approx. $27.2 \%$, while in the second heating scan the cold crystallization peak is more evident. Furthermore, concerning P12F, during the cooling scan, a cold crystallization peak was measured and it is quite similar to the melting peak related to $\mathrm{P} 12 \mathrm{~F}$, and therefore it is reasonable to state that the cold crystallization peak in the second heating scan is related only to PLA. It could be also interesting to understand how the crystallinity of PLA is affected by the introduction of P12F. Considering $\chi_{\text {PLA }}$ values of the blends reported in Table 4, it is possible to notice that the crystallinity of the PLA phase progressively increases with the P12F concentration, passing from $27.2 \%$ of the neat PLA up to $34.9 \%$ for the PLA_30P12F fiber blend. It can be therefore concluded 


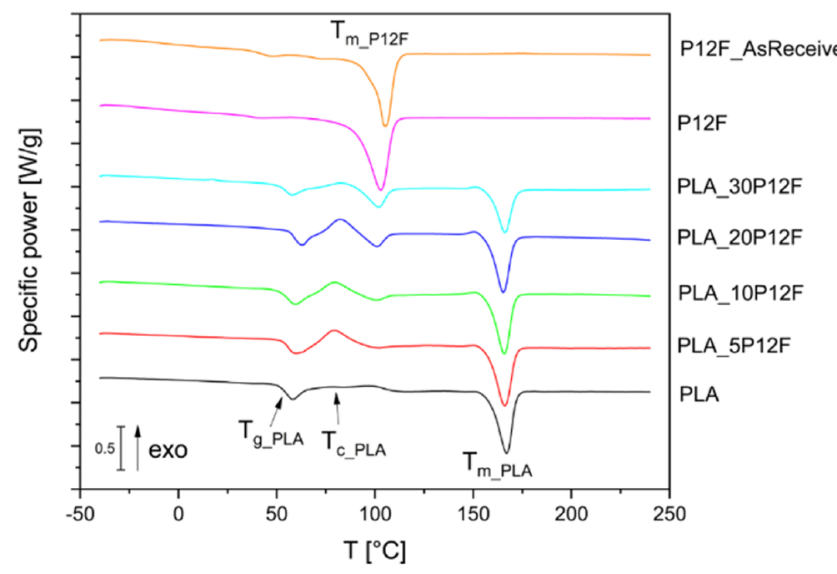

(a)

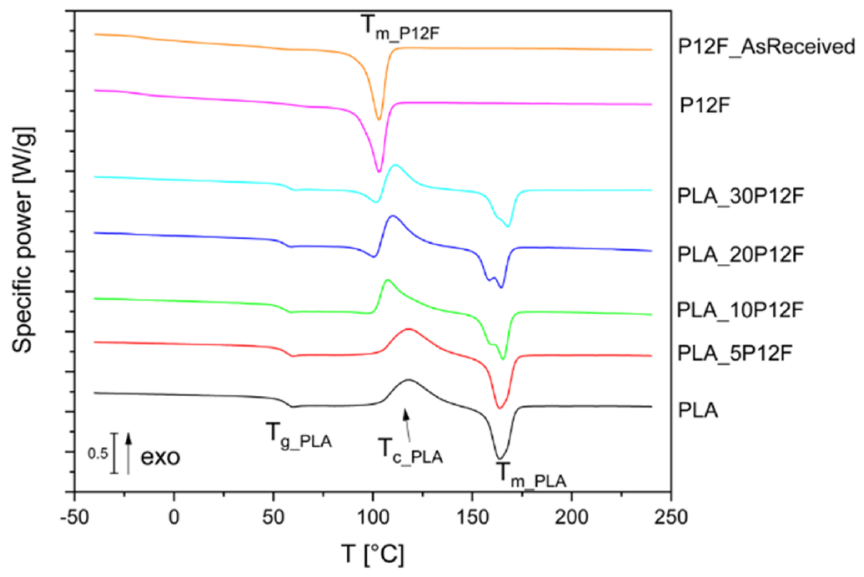

(b)

Fig. 5 DSC thermograms of P12F as received, P12F fiber, PLA fiber, and PLA_xP12F fiber blends ( $\mathrm{x}=5-30$ wt\%). a First heating scan, $\mathbf{b}$ second heating scan

that P12F domains within the PLA matrix play a nucleating effect, improving thus the crystallinity content. From the $\mathrm{T}_{\mathrm{C}_{\text {PLAA }}}$ results reported in Table 4 , it can be also noticed that the crystallization temperature of PLA is decreased upon the $\mathrm{P} 12 \mathrm{~F}$ introduction. In the first heating scan, it can be seen that $\mathrm{T}_{\mathrm{C}}$ values of PLA phase pass from $96.5^{\circ} \mathrm{C}$ up to 83.3 ${ }^{\circ} \mathrm{C}$ with a $\mathrm{P} 12 \mathrm{~F}$ content of $30 \mathrm{wt} \%$, and a similar trend can be seen also in the second heating scan. This result confirms the nucleating effect played by P12F domains within the PLA matrix. However, further analyses will be necessary in the future to have a better comprehension of the crystallization behaviour of PLA in these blends.

Figure 6 shows the TGA thermograms and DTG curves of both PLA_xP8F (Fig. 6a, b) and PLA_xP12F (Fig. 6c, d) fiber blends ( $\mathrm{x}=5-30 \mathrm{wt} \%)$, while the most important results are collected in Table 5. In both PLA_xP8F and PLA_xP12F thermograms (Fig. 6a, c) it is possible to notice a mass loss starting from approximately $100{ }^{\circ} \mathrm{C}$. This mass loss is certainly linked to the evaporation of the water absorbed by the blends. In the case of PLA_xP8F samples, the addition of P8F does not lower the water absorption tendency of PLA. On the other hand, as it is possible to notice in Fig. 6c, as the content of P12F increases in the PLA_xP12F fiber blends, the step related to water loss tends to decrease, which suggests that the addition of $\mathrm{P} 12 \mathrm{~F}$ in the blends helps in reducing the water absorption tendency of PLA. All the samples lose the majority of their mass between $300{ }^{\circ} \mathrm{C}$ and $400{ }^{\circ} \mathrm{C}$. PLA_xP8F fiber blends show the DTG peak linked to PLA at approximately $370{ }^{\circ} \mathrm{C}$ while at a slightly higher temperature, approximately $400{ }^{\circ} \mathrm{C}$, it is possible to notice a small side peak probably associated with the P8F decomposition temperature, as reported in literature [30].

Regarding PLA_xP12F fiber blends, the DTG curves reported in Fig. 6d highlights a peak related to PLA degradation at approximately $370{ }^{\circ} \mathrm{C}$, while the peak associated with the $\mathrm{P} 12 \mathrm{~F}$ phase is approximately at $408^{\circ} \mathrm{C}$. $\mathrm{P} 12 \mathrm{~F}$ presents the steepest degradation step among all the tested fiber blends. As reported in the work of Bikiaris et al. [61], the thermal stability of both P8F and P12F is similar to that of PEF, PPF, and PHF but slightly higher than that of PBF. In conclusion, it is possible to notice from the data reported in Table 5 that the thermal stability of PLA is not substantially affected by the presence of both P8F and P12F. Furthermore, the $m_{700}$ values tend to increase by increasing the PAF content in the blends, and they are systematically higher for PLA/P12F blends in comparison to PLA/P8F ones.

Figure $7 \mathrm{a}, \mathrm{b}$ show representative stress-strain curves of neat PLA and the relative PLA_xP8F (Fig. 7a) and PLA_xP12F fiber blends (Fig. 7b). Furthermore, the most important results are collected in Table 6. The stress-strain curves reported in Fig. 7a, b possess a rather low signal-tonoise ratio, since the load cell selected was characterized by high sensitivity and therefore the local environmental noise was also detected. Nevertheless, the low signal-tonoise ratio did not dramatically affect the quality of the obtained results. As expected, PLA fibers show a quite high modulus $(2.2 \mathrm{GPa})$ and interesting failure properties $\left(\sigma_{b}=30.1 \mathrm{MPa},=\varepsilon_{b} 127 \%\right)$ [62]. On the other hand, the mechanical properties of PLA_xP8F fibers tend to decrease by increasing the content of P8F. At elevated P8F concentrations (30 wt $\%$ ), the ductility of the fiber is completely lost since $\varepsilon_{b}$ decreases to $1.6 \%$, and also $\sigma_{b}$ of the fiber drops down to 7.2 $\mathrm{MPa}$. The cause of the observed decrease in the mechanical properties may be the low interfacial adhesion between P8F domains and PLA matrix, especially at elevated P8F amounts. In the work of Jompang et al. [63], PLA and poly(butylene succinate) (PBS) fiber blends were prepared through melt spinning, 


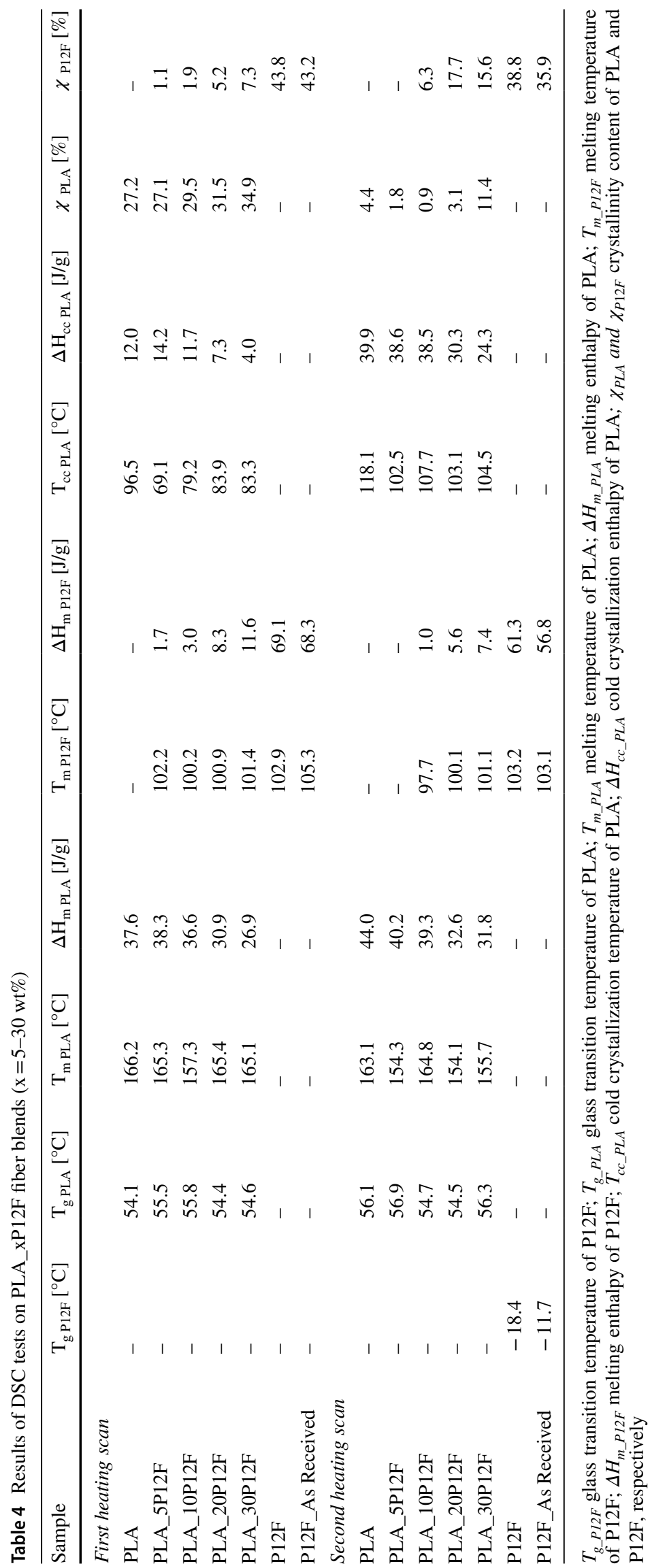




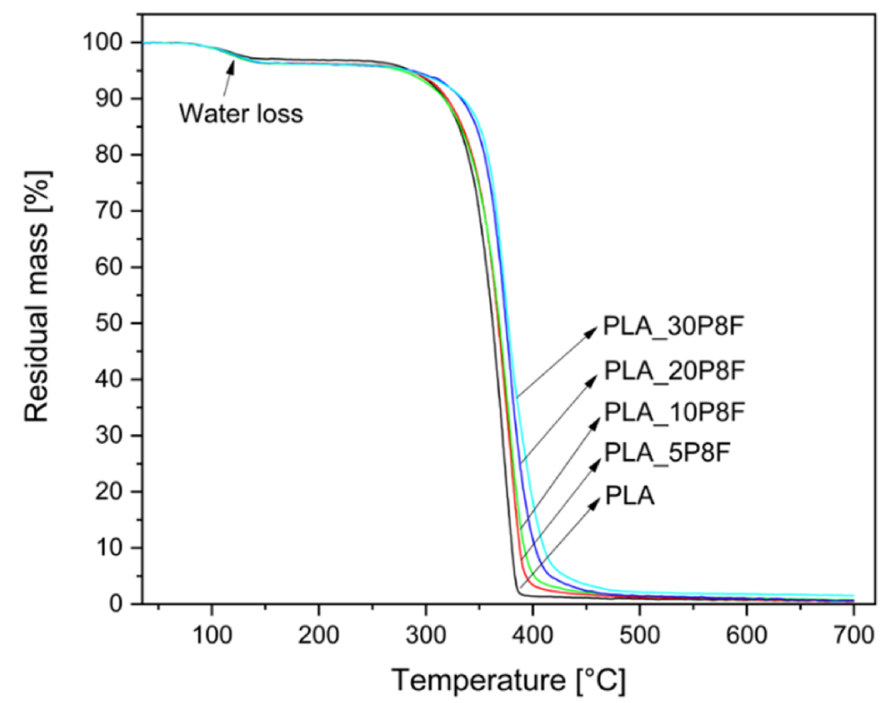

(a)

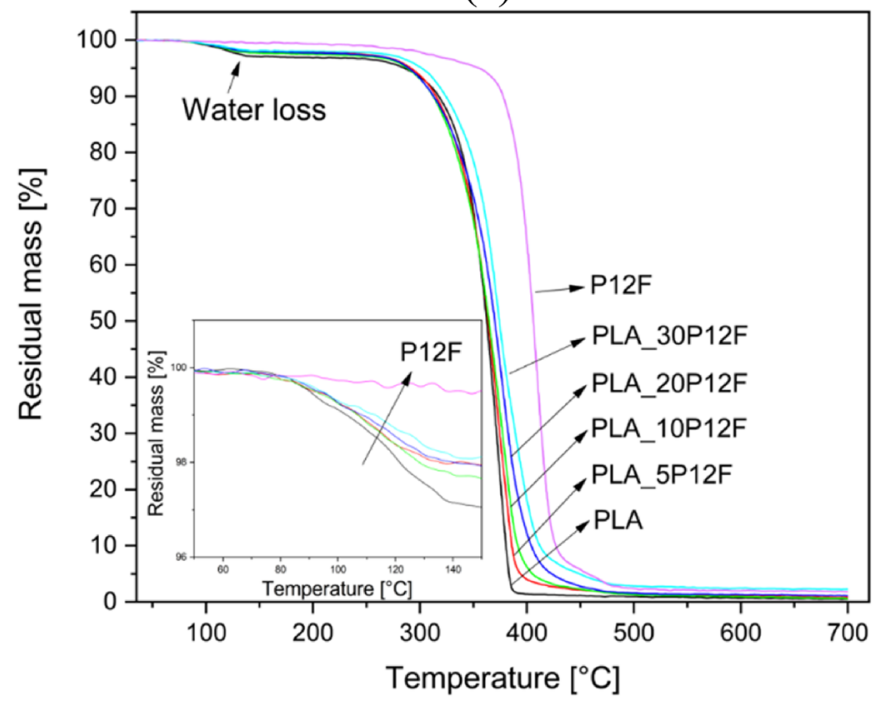

(c)

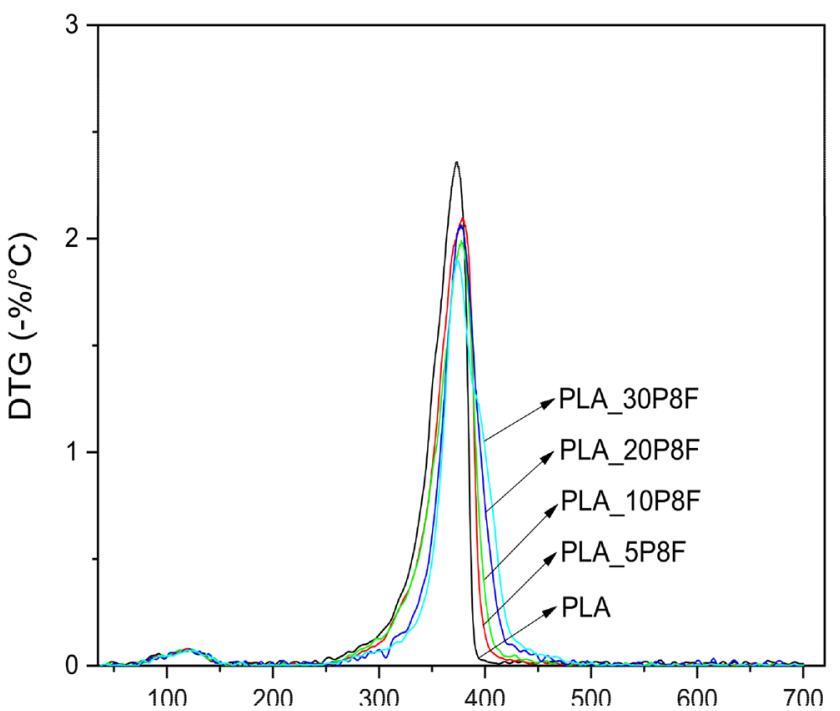

(b)

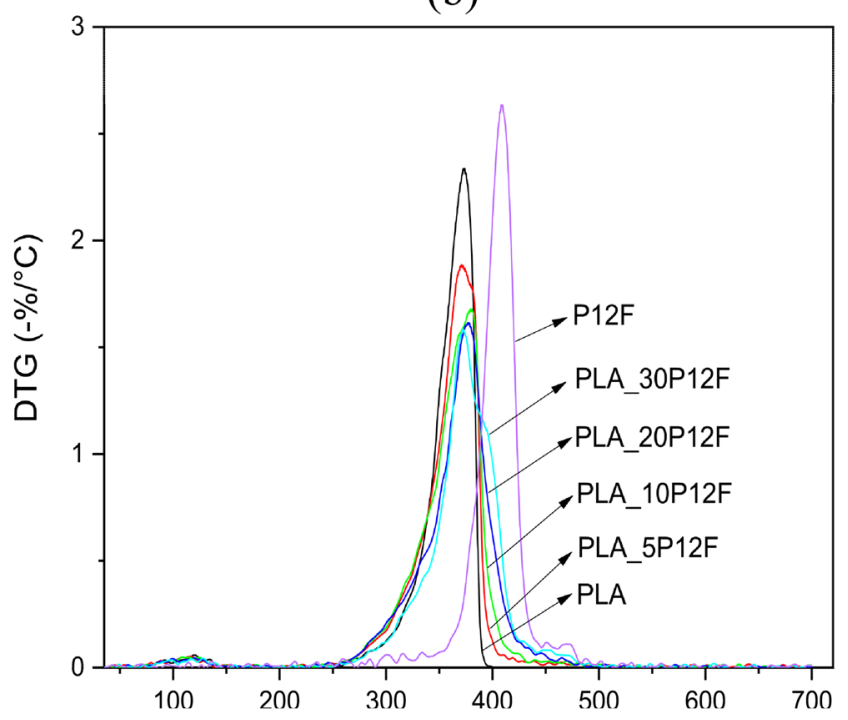

(d)

Fig. 6 TGA thermograms of neat PLA and relative fiber blends. a Residual mass of PLA_xP8F samples, $\mathbf{b}$ mass loss derivative of PLA_xP8F samples, $\mathbf{c}$ residual mass of PLA_xP12F samples, $\mathbf{d}$ mass loss derivative of PLA_xP12F samples ( $\mathrm{x}=5-30 \mathrm{wt} \%)$

and they reported a decrease in the mechanical properties as the content of PBS was increased. Also in that work the observed drop was attributed to the low adhesion between PBS and the PLA matrix. On the other hand, the values of $E, \sigma_{y}$, and $\sigma_{b}$ of the PLA_xP12F blends (Fig. 7b) are approximately constant by increasing P12F content (and in some cases also slightly enhanced), while the $\varepsilon_{b}$ is decreased. However, the observed decrease in the failure strain is not dramatic, neither at elevated P12F amounts. It is also interesting to notice that neat P12F fibers were not broken during the tensile tests, since the maximum elongation achievable with the utilized testing equipment has been reached. In particular, PLA_30P12F sample has an elastic modulus of $2.2 \mathrm{GPa}$ and a stress at break of 32 MPa. Even if P12F possesses an extremely high ductility $\left(\varepsilon_{b}>240 \%\right)$, the failure strain of this blend decreases to $46 \%$. The relatively low ductility of PLA/P12F fiber blends may be correlated to relatively poor adhesion between the P12F domains and PLA matrix. One of the strategies to improve the adhesion between two polymer phases, which was extensively studied in literature [64], is to use compatibilizers, such as maleic anhydride-functionalized polymers, to enhance the affinity between the two phases. It could be also possible to work on the production of PLA/ PFAs blends with small amount of different nanofillers, 
Table 5 Results of the TGA tests of the PLA_xP8F and PLA_xP12F fiber blends $(x=5-30 \mathrm{wt} \%)$

\begin{tabular}{llll}
\hline Sample & $m_{\mathrm{H}_{2} \mathrm{O}}[\%]$ & $T_{D}\left[{ }^{\circ} \mathrm{C}\right]$ & $m_{700}[\%]$ \\
\hline PLA & 3.1 & 373.7 & 0.49 \\
PLA_5P8F & 3.7 & 378.3 & 0.53 \\
PLA_10 P8F & 3.9 & 377.3 & 0.81 \\
PLA_20 P8F & 3.8 & 377.7 & 0.62 \\
PLA_30P8F & 3.8 & 374.7 & 1.51 \\
PLA & 3.1 & 373.7 & 0.49 \\
PLA_5P12F & 2.2 & 370.8 & 0.79 \\
PLA_10P12F & 2.5 & 379.3 & 0.57 \\
PLA_20P12F & 2.2 & 377.2 & 1.13 \\
PLA_30P12F & 1.9 & 372.7 & 2.27 \\
P12F & 0.6 & 408.3 & 1.81 \\
\hline
\end{tabular}

$m_{\mathrm{H}_{2} \mathrm{O}}$ water loss; $T_{D}$ degradation temperature; $m_{700}$ residual mass at $700{ }^{\circ} \mathrm{C}$

such as nanosilica, nanocellulose, or carbon nanotubes, in order to improve the affinity between the constituents and reducing the size of the dispersed polymer phase (i.e. the minoritary component).

\section{Characterization of the Drawn Fibers}

According to the results obtained through the mechanical characterization of the as-spun fibers, the most promising ones were the PLA/P12F blends, because even at relatively high $\mathrm{P} 12 \mathrm{~F}$ contents the stiffness and the stress at break of the neat PLA were not negatively affected (and in some cases also slightly improved), while the observed elongation at break was not dramatically decreased. Knowing that both the microstructural features and the mechanical properties of the fibers could be strongly affected by the drawing process, it was decided to prepare neat PLA and PLA_20P12F drawn fibers at two different DR levels. Figure 8a, b report the LM micrographs of the cross-section of the fibers drawn applying a DR equal to 2.7. As already seen in the case of the as-spun fibers (see Fig. 2), also drawn fibers possess an elliptical cross-section, but with a less pronounced eccentricity. The mean diameter of PLA_D2.7 fibers is $41 \pm 2 \mu \mathrm{m}(-43 \%$ with respect to the as-spun PLA fibers), while the diameter of PLA_20P12F_D2.7 fibers is $53 \pm 3 \mu \mathrm{m}(-43 \%$ with respect to the as-spun PLA_20P12F fiber blends). Moreover, from Fig. $8 \mathrm{~b}$ it is evident that the diameter of $\mathrm{P} 12 \mathrm{~F}$ domains within the PLA matrix decreases from $3.0 \pm 0.9$ $\mu \mathrm{m}$ up to $1.7 \pm 0.7 \mu \mathrm{m}(-43 \%)$. The overall decrease in the mean diameter of the fibers and also the drop in the diameter of P12F domains within the PLA matrix is a direct consequence of the drawing process.

Figure 9 reports a comparison between the stress-strain curves of the PLA and PLA_20P12F fibers, before and after the drawing process, while the most important results are summarized in Table 7. As it could be expected, the drawing process performed at $70{ }^{\circ} \mathrm{C}$ noticeably improves the mechanical properties of the fibers, regardless of the presence of P12F in the samples. As expected, the increase of the applied DR produces a systematic enhancement of all the mechanical properties of the fibers. Blend containing $20 \mathrm{wt} \%$ of P12F and drawn with a nominal DR of 1.7 and 2.7 show an improvement of $E$ by $24 \%$ and $76 \%$, of

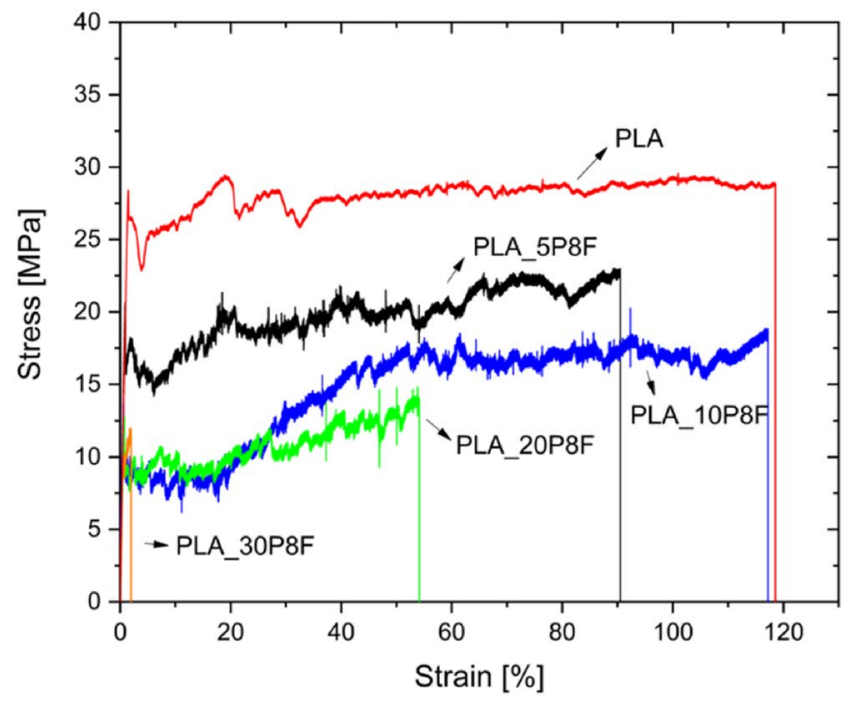

(a)

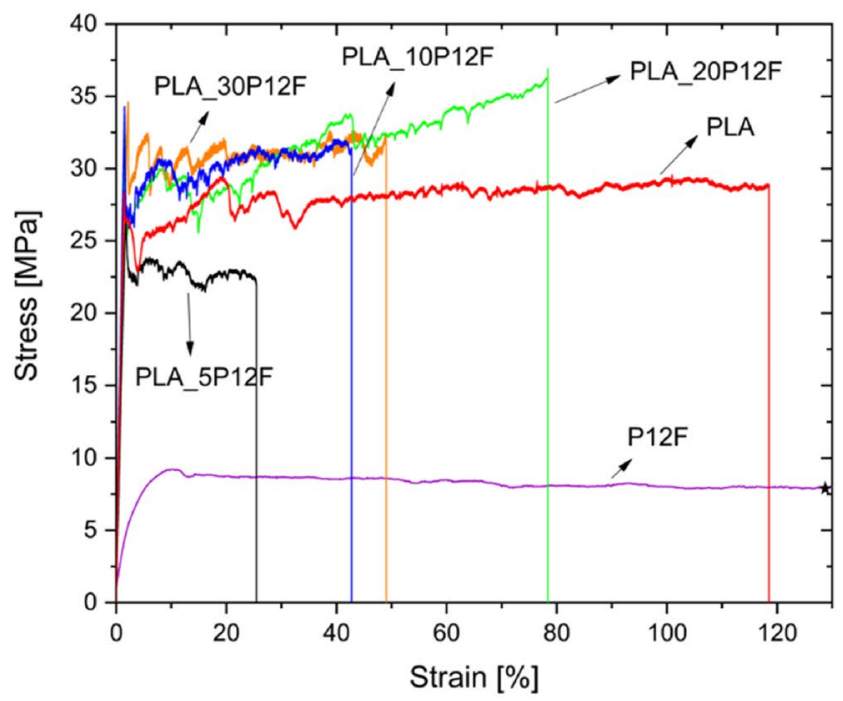

(b)

Fig. 7 Stress-strain curves of a PLA_xP8F and b PLA_xP12F fiber blends ( $x=5-30 \mathrm{wt} \%$ ) ( $*=$ not broken sample). 
Table 6 Results of tensile tests on the PLA_xP8F and PLA_xP12F fiber blends ( $\mathrm{x}=5-30 \mathrm{wt} \%)$

\begin{tabular}{lcrll}
\hline Sample & $E[\mathrm{GPa}]$ & \multicolumn{1}{c}{$\sigma_{Y}[\mathrm{MPa}]$} & $\sigma_{b}[\mathrm{MPa}]$ & $\varepsilon_{b}[\%]$ \\
\hline PLA & $2.2 \pm 0.4$ & $30.6 \pm 3.9$ & $30.1 \pm 4.1$ & $127 \pm 48$ \\
PLA_5P8F & $1.9 \pm 0.3$ & $17.6 \pm 4.4$ & $17.0 \pm 4.6$ & $101 \pm 31$ \\
PLA_10P8F & $2.0 \pm 0.4$ & $14.9 \pm 2.0$ & $15.6 \pm 3.2$ & $88 \pm 45$ \\
PLA_20P8F & $1.4 \pm 0.3$ & $12.4 \pm 3.8$ & $14.3 \pm 3.5$ & $56 \pm 22$ \\
PLA_30P8F & $1.5 \pm 0.9$ & $5.1 \pm 3.2$ & $7.2 \pm 5.2$ & $1.6 \pm 1.0$ \\
PLA & $2.2 \pm 0.4$ & $30.6 \pm 3.9$ & $30.1 \pm 4.1$ & $127 \pm 48$ \\
PLA_5P12F & $2.2 \pm 0.4$ & $26.5 \pm 6.4$ & $25.0 \pm 4.2$ & $28 \pm 10$ \\
PLA_10P12F & $1.8 \pm 0.4$ & $25.2 \pm 5.1$ & $25.0 \pm 3.2$ & $43 \pm 14$ \\
PLA_20P12F & $2.5 \pm 0.6$ & $35.2 \pm 8.4$ & $36.5 \pm 8.4$ & $76 \pm 26$ \\
PLA_30P12F & $2.2 \pm 0.5$ & $33.8 \pm 7.6$ & $31.9 \pm 5.4$ & $46 \pm 13$ \\
P12F & $0.2 \pm 0.1$ & $8.6 \pm 0.5$ & - & $>240$ \\
\hline
\end{tabular}

$E$ elastic modulus; $\sigma_{y}$ yield stress; $\sigma_{b}$ stress at break; $\varepsilon_{b}$ strain at break
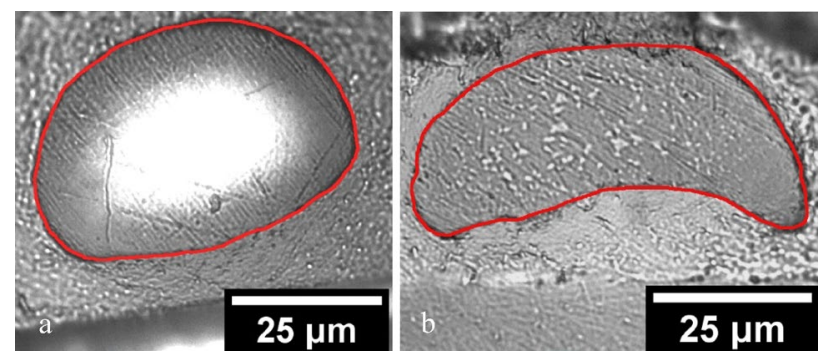

Fig. 8 Light microscope images of the polished cross-section of the drawn fibers (the contour of the fibers was highlighted in red for better clarity). a PLA_D2.7, b PLA_20P12F_D2.7

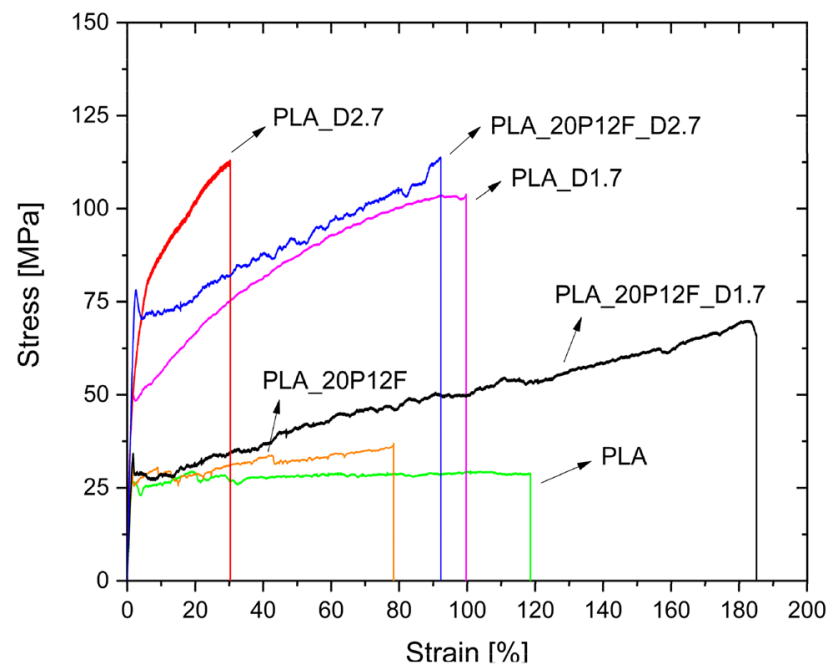

Fig. 9 Comparison between the stress-strain curves of the as-spun and drawn PLA and PLA_20P12F fibers
Table 7 Results of tensile tests on the drawn fibers

\begin{tabular}{llcr}
\hline Sample & $E[\mathrm{GPa}]$ & $\sigma_{b}[\mathrm{MPa}]$ & \multicolumn{1}{c}{$\varepsilon_{b}[\%]$} \\
\hline PLA_D1.7 & $3.9 \pm 0.1$ & $98.7 \pm 4.3$ & $74 \pm 23$ \\
PLA_20P12F_D1.7 & $3.1 \pm 0.6$ & $65.0 \pm 2.9$ & $224 \pm 59$ \\
PLA_D2.7 & $5.1 \pm 1.1$ & $128.2 \pm 15.7$ & $39 \pm 18$ \\
PLA_20P12F_D2.7 & $4.4 \pm 0.2$ & $107.3 \pm 22.5$ & $86 \pm 29$ \\
\hline
\end{tabular}

$E$ elastic modulus; $\sigma_{\mathrm{b}}$ stress at break; $\varepsilon_{\mathrm{b}}$ strain at break

$\sigma_{b}$ by $78 \%$ and $194 \%$, and of $\varepsilon_{b}$ by $195 \%$ and $13 \%$, respectively, in comparison to the as-spun PLA_20P12F fibers. Neat PLA fibers drawn with a nominal DR of 1.7 and 2.7 have an increase of $E$ by $77 \%$ and $127 \%$, of $\sigma_{b}$ by $228 \%$ and $326 \%$, and a decrease of $\varepsilon_{b}$ by $42 \%$ and $69 \%$, respectively, with respect to the as-spun PLA fibers. As expected, the fibers drawn with a nominal DR of 2.7 reported enhanced mechanical properties and lower $\varepsilon_{b}$ in comparison to the fibers drawn with a nominal DR of 1.7. This is caused by the fact that higher DR means a higher orientation of the macromolecules and therefore improved mechanical properties, as reported in several publications [65, 66]. It could be hypothesized that the observed increase of the elastic modulus and of the stress at break upon the drawing process could be related to an increase of the crystallinity of the constituents. However, it was not possible to test the drawn fibers through DSC tests, because of the low amount of available material, and XRD tests were not able to elucidate these aspects in a satisfactory way. Further tests will be needed to explain the observed trend. Considering the effect of the $\mathrm{P} 12 \mathrm{~F}$ on the mechanical properties of the drawn fibers, it can be observed that the stiffness and the stress at break values of the PLA_20P12F are not so far from those of the neat PLA fibers, at both DR levels. Interesting and unexpected results were instead obtained considering failure strain data. The elongation at break of the PLA_20P12F fiber blends dramatically increases by increasing the nominal DR, and $\varepsilon_{\mathrm{b}}$ values are considerably higher than those of neat PLA fibers. The peculiar behavior concerning the elongation at break has been already observed for several amorphous polymers [67] and blends [68]. The observed increase in the elongation at break values of the drawn fiber blends may be linked to the fact that the drawing process performed at $70{ }^{\circ} \mathrm{C}$ might have improved the adhesion between P12F domains and PLA matrix, and therefore, during the application of a tensile load, a better load distribution on the P12F domains can be realized. Since neat P12F fiber reports an extremely high elongation at break (see Table 6), the overall elongation at break of the fiber blends tends to significantly increase if the load distribution is performed more efficiently. Another possible explanation for the observed increase of the elongation at break can be found in the paper of La Mantia et al. [68] on polyethylene (PE)/polyamide 6 (PA6) blends. In that work 
it was shown that these two polymers were immiscible, and during the application of a tensile load, the PA6 domains acted as defects, worsening thus of the mechanical properties of the blends. After the drawing process, the PA6 domains inside the matrix were elongated and oriented in the same direction. In these conditions, the worsening effect provided by the PA6 domains was mitigated [68]. Regarding PLA/ $\mathrm{P} 12 \mathrm{~F}$ fiber blends prepared in this work, it is possible to hypothesize that during the drawing process, $\mathrm{P} 12 \mathrm{~F}$ domains have been elongated toward the drawing direction. In fact, from the LM images reported in Fig. 8b it is possible to notice that the mean diameter of the P12F domains within drawn fibers is significantly decreased. Consequently, the defect-like nature of the P12F domains is mitigated, and the elongation at break values considerably improved.

In conclusion, by comparing PLA and PLA_20P12F drawn fibers, it is possible to state that $\mathrm{P} 12 \mathrm{~F}$ introduction helps in improving the ductility of the PLA fibers, if properly drawn, without substantially impairing their stiffness and stress at break values. Further improvements could be obtained in the future by an optimization of the drawing conditions. The prepared fibers blends could be therefore interesting for the development of novel sustainable textiles with improved mechanical features.

\section{Conclusions}

The present work investigated for the first time the microstructural, thermal and mechanical properties of novel biobased fiber blends, constituted by PLA and two furan based matrices, i.e., poly(1,12-dodecylene 2,5-furandicarboxylate) (P12F) and poly(1,8-octylene 2,5-furandicarboxylate) (P8F), produced through wet spinning process. The microstructural characterization performed on the asspun fibers evidenced that both PLA/P8F and PLA/P12F fiber blends were immiscible, with PAF domains homogeneously dispersed within the PLA matrix. DSC analysis highlighted that the degree of crystallinity of both PLA and P12F phases tended to increase with the P12F content. TGA analysis showed that the thermal stability of PLA was practically unaltered by the presence of either P8F or P12F. Besides, P12F helped to decrease the water absorption tendency of PLA. Tensile tests evidenced a steep decrease in the mechanical properties by increasing the P8F content for PLA_xP8F fiber blends, probably correlated to the low adhesion between the P8F domains and the PLA matrix. On the other hand, PLA_xP12F fiber blends reported mechanical properties comparable to that of neat PLA fibers, without a dramatic drop of the failure strain.

Microstructural analysis on the drawn fibers showed that the mean diameter of the P12F domains within the PLA matrix decreased by $43 \%$ with respect to the as-spun fibers.
Tensile tests evidenced that both the elastic modulus and the stress at break of PLA_20P12F drawn fibers were slightly lower in comparison to PLA drawn fibers. On the other hand, the strain at break of PLA_20P12F drawn fibers increased by $303 \%$ and $220 \%$ compared to PLA fibers when the nominal DR was of 1.7 and 2.7, respectively. The improvement in the strain at break of the fiber blends upon the drawing process was probably correlated to a progressive deformation of P12F domains along the strain direction, promoting a better adhesion between the P12F domains and the PLA matrix. In conclusion, the addition of P12F to PLA has been proven to be very successful in improving the strain at break of the produced fibers after the drawing process, without significantly decreasing the stiffness and the strength of the PLA fibers. This study contributed to improving the knowledge about bioderived furan-based polymers and the relative blends with PLA, and elucidated also the effect of the drawing process on the microstructural and mechanical features of the prepared fibers. According to the obtained results, these fibers could be a good candidate for the replacement of polyester fibers traditionally applied in textile or packaging sector.

Author Contributions All authors contributed to the study conception and design. Material preparation, data collection and analysis were performed by DP. The first draft of the manuscript was written by DP and all authors commented on previous versions of the manuscript. All authors read and approved the final manuscript.

Funding Open access funding provided by Università degli Studi di Trento within the CRUI-CARE Agreement. L'Oréal-UNESCO For Women In Science is gratefully acknowledged for financial support. This publication is based upon work from COST Action FUR4Sustain, CA18220, supported by COST (European Cooperation in Science and Technology).

Data Availability Data and materials are available under requests.

\section{Declarations}

Conflict of interest The authors declare that they have no known competing financial interests or personal relationships that could have appeared to influence the work reported in this paper.

Open Access This article is licensed under a Creative Commons Attribution 4.0 International License, which permits use, sharing, adaptation, distribution and reproduction in any medium or format, as long as you give appropriate credit to the original author(s) and the source, provide a link to the Creative Commons licence, and indicate if changes were made. The images or other third party material in this article are included in the article's Creative Commons licence, unless indicated otherwise in a credit line to the material. If material is not included in the article's Creative Commons licence and your intended use is not permitted by statutory regulation or exceeds the permitted use, you will need to obtain permission directly from the copyright holder. To view a copy of this licence, visit http://creativecommons.org/licenses/by/4.0/. 


\section{References}

1. Borrelle SB, Rochman CM, Liboiron M, Bond AL, Lusher A, Bradshaw H, Provencher JF (2017) Opinion: why we need an international agreement on marine plastic pollution. Proc Natl Acad Sci 114:9994-9997. https://doi.org/10.1073/pnas.17144 50114

2. Gross M (2017) Our planet wrapped in plastic. Curr Biol 27:R785-R788. https://doi.org/10.1016/j.cub.2017.08.007

3. Peelman N, Ragaert P, De Meulenaer B, Adons D, Peeters R, Cardon L, Van Impe F, Devlieghere F (2013) Application of bioplastics for food packaging. Trends Food Sci Technol 32:128-141. https://doi.org/10.1016/j.tifs.2013.06.003

4. Van Beilen JB, Poirier Y (2008) Production of renewable polymers from crop plants. Plant J 54:684-701. https://doi.org/10. 1111/j.1365-313X.2008.03431.x

5. Chen G-Q, Patel MK (2012) Plastics derived from biological sources: present and future: a technical and environmental review. Chem Rev 112:2082-2099. https://doi.org/10.1021/cr200162d

6. MacGregor EA (2003) Biopolymers. In: Meyers RA (ed) Encyclopedia of physical science and technology, vol 207-245, 3rd edn. Academic Press, London

7. Garlotta D (2001) A literature review of poly(lactic acid). J Polym Environ 9:63-84. https://doi.org/10.1023/A:1020200822435

8. Raza ZA, Abid S, Banat IM (2018) Polyhydroxyalkanoates: characteristics, production, recent developments and applications. Int Biodeterior Biodegradation 126:45-56. https://doi.org/10.1016/j. ibiod.2017.10.001

9. Dorigato A, Perin D, Pegoretti A (2020) Effect of the temperature and of the drawing conditions on the fracture behaviour of thermoplastic starch films for packaging applications. J Polym Environ 28:3244-3255. https://doi.org/10.1007/s10924-020-01843-3

10. Lasprilla AJR, Martinez GAR, Lunelli BH, Jardini AL, Filho RM (2012) Poly-lactic acid synthesis for application in biomedical devices-a review. Biotechnol Adv 30:321-328. https://doi.org/ 10.1016/j.biotechadv.2011.06.019

11. Avérous L (2008) Chapter 21—polylactic acid: synthesis, properties and applications. In: Belgacem MN, Gandini A (eds) Monomers, polymers and composites from renewable resources, vol 433-450. Elsevier, Amsterdam

12. Hu J, Wang J, Wang M, Ozaki Y, Sato H, Zhang J (2019) Investigation of crystallization behavior of asymmetric PLLA/PDLA blend using Raman imaging measurement. Polymer 172:1-6. https://doi.org/10.1016/j.polymer.2019.03.049

13. Kobayashi J, Asahi T, Ichiki M, Oikawa A, Suzuki H, Watanabe T, Fukada E, Shikinami Y (1995) Structural and optical properties of poly lactic acids. J Appl Phys 77:2957-2973. https://doi.org/ $10.1063 / 1.358712$

14. Maharana T, Mohanty B, Negi YS (2009) Melt-solid polycondensation of lactic acid and its biodegradability. Prog Polym Sci 34:99-124. https://doi.org/10.1016/j.progpolymsci.2008.10.001

15. Jamshidian M, Tehrany EA, Imran M, Jacquot M, Desobry S (2010) Poly-lactic acid: production, applications, nanocomposites, and release studies. Compr Rev Food Sci Food Safety 9:552-571. https://doi.org/10.1111/j.1541-4337.2010.00126.x

16. Shi X, Qin J, Wang L, Ren L, Rong F, Li D, Wang R, Zhang G (2018) Introduction of stereocomplex crystallites of PLA for the solid and microcellular poly(lactide)/poly(butylene adipate-coterephthalate) blends. RSC Adv 8:11850-11861. https://doi.org/ 10.1039/C8RA01570H

17. Cho J, Baratian S, Kim J, Yeh F, Hsiao BS, Runt J (2003) Crystallization and structure formation of poly(L-lactide-co-meso-lactide) random copolymers: a time-resolved wide- and small-angle $\mathrm{X}$-ray scattering study. Polymer 44:711-717. https://doi.org/10.1016/ S0032-3861(02)00823-6
18. Tait M, Pegoretti A, Dorigato A, Kalaitzidou K (2011) The effect of filler type and content and the manufacturing process on the performance of multifunctional carbon/poly-lactide composites. Carbon 49:4280-4290. https://doi.org/10.1016/j.carbon.2011.06. 009

19. Dorigato A, Sebastiani M, Pegoretti A, Fambri L (2012) Effect of silica nanoparticles on the mechanical performances of poly(lactic acid). J Polym Environ 20:713-725. https://doi.org/10.1007/ s10924-012-0425-6

20. Fambri L, Dorigato A, Pegoretti A (2020) Role of surfacetreated silica nanoparticles on the thermo-mechanical behavior of poly(lactide). Appl Sci 10:6731. https://doi.org/10.3390/app10 196731

21. Sousa AF, Vilela C, Fonseca AC, Matos M, Freire CSR, Gruter G-JM, Coelho JFJ, Silvestre AJD (2015) Biobased polyesters and other polymers from 2,5-furandicarboxylic acid: a tribute to furan excellency. Polym Chem 6:5961-5983. https://doi.org/10.1039/ C5PY00686D

22. Papageorgiou GZ, Papageorgiou DG, Terzopoulou Z, Bikiaris DN (2016) Production of bio-based 2,5-furan dicarboxylate polyesters: recent progress and critical aspects in their synthesis and thermal properties. Eur Polymer J 83:202-229. https:// doi.org/10.1016/j.eurpolymj.2016.08.004

23. Terzopoulou Z, Papadopoulos L, Zamboulis A, Papageorgiou DG, Papageorgiou GZ, Bikiaris DN (2020) Tuning the properties of furandicarboxylic acid-based polyesters with copolymerization: a review. Polymers 12:1209. https://doi.org/10.3390/ polym 12061209

24. Sajid M, Zhao X, Liu D (2018) Production of 2,5-furandicarboxylic acid (FDCA) from 5-hydroxymethylfurfural (HMF): recent progress focusing on the chemical-catalytic routes. Green Chem 20:5427-5453. https://doi.org/10.1039/C8GC02680G

25. Eerhart AJJE, Faaij APC, Patel MK (2012) Replacing fossil based pet with biobased PEF; process analysis, energy and GHG balance. Energy Environ Sci 5:6407-6422. https://doi.org/10. 1039/C2EE02480B

26. Gandini A, Silvestre AJD, Neto CP, Sousa AF, Gomes M (2009) The furan counterpart of poly(ethylene terephthalate): an alternative material based on renewable resources. J Polym Sci 47:295-298. https://doi.org/10.1002/pola.23130

27. Vannini M, Marchese P, Celli A, Lorenzetti C (2015) Fully biobased poly (propylene 2,5-furandicarboxylate) for packaging applications: excellent barrier properties as a function of crystallinity. Green Chem 17:4162-4166. https://doi.org/10. 1039/C5GC00991J

28. Papageorgiou GZ, Tsanaktsis V, Papageorgiou DG, Exarhopoulos S, Papageorgiou M, Bikiaris DN (2014) Evaluation of polyesters from renewable resources as alternatives to the current fossil-based polymers. Phase transitions of poly(butylene 2,5-furan-dicarboxylate). Polymer 55:3846-3858. https://doi. org/10.1016/j.polymer.2014.06.025

29. Ma J, Pang Y, Wang M, Xu J, Ma H, Nie X (2012) The copolymerization reactivity of diols with 2,5-furandicarboxylic acid for furan-based copolyester materials. J Mater Chem 22:34573461. https://doi.org/10.1039/C2JM15457A

30. Papageorgiou G, Guigo N, Tsanaktsis V, Papageorgiou D, Exarhopoulos S, Sbirrazzuoli N, Bikiaris D (2015) On the bio-based furanic polyesters: synthesis and thermal behavior study of poly(octylene furanoate) using fast and temperature modulated scanning calorimetry. Eur Polymer J 68:115-127. https://doi. org/10.1016/j.eurpolymj.2015.04.011

31. Tsanaktsis V, Bikiaris DN, Guigo N, Exarhopoulos S, Papageorgiou DG, Sbirrazzuoli N, Papageorgiou GZ (2015) Synthesis, properties and thermal behavior of poly(decylene-2,5furanoate): a biobased polyester from 2,5-furan dicarboxylic 
acid. RSC Adv 5:74592-74604. https://doi.org/10.1039/C5RA1 $3324 \mathrm{~F}$

32. Fredi G, Dorigato A, Bortolotti M, Pegoretti A, Bikiaris D (2020) Mechanical and functional properties of novel biobased poly(decylene-2,5-furanoate)/carbon nanotubes nanocomposite films. Polymers 12:2459. https://doi.org/10.3390/polym12112459

33. Papageorgiou DG, Guigo N, Tsanaktsis V, Exarhopoulos S, Bikiaris DN, Sbirrazzuoli N, Papageorgiou GZ (2016) Fast crystallization and melting behavior of a long-spaced aliphatic furandicarboxylate biobased polyester, poly(dodecylene 2,5-furanoate). Ind Eng Chem Res 55:5315-5326. https://doi.org/10.1021/acs. iecr.6b00811

34. Gomes M, Gandini A, Silvestre AJD, Reis B (2011) Synthesis and characterization of poly(2,5-furan dicarboxylate)s based on a variety of diols. J Polym Sci, Part A Polym Chem 49:3759-3768. https://doi.org/10.1002/pola.24812

35. Papamokos G, Dimitriadis T, Bikiaris DN, Papageorgiou GZ, Floudas G (2019) Chain conformation, molecular dynamics, and thermal properties of poly(n-methylene 2,5-furanoates) as a function of methylene unit sequence length. Macromolecules 52:6533-6546. https://doi.org/10.1021/acs.macromol.9b01320

36. Hassan A, Balakrishnan H, Akbari A (2013) Polylactic acid based blends, composites and nanocomposites. In: Thomas S, Visakh PM, Mathew AP (eds) Advances in natural polymers: composites and nanocomposites, vol 361-396. Springer, Berlin, Heidelberg

37. Fredrickson GH, Liu AJ, Bates FS (1994) Entropic corrections to the Flory-Huggins theory of polymer blends: architectural and conformational effects. Macromolecules 27:2503-2511. https:// doi.org/10.1021/ma00087a019

38. Qin Y (2016) 5-applications of advanced technologies in the development of functional medical textile materials. Medical textile materials, vol 55-70. Woodhead Publishing, Sawston

39. Wang L, Ma W, Gross RA, McCarthy SP (1998) Reactive compatibilization of biodegradable blends of poly(lactic acid) and poly( $\varepsilon$-caprolactone). Polym Degrad Stab 59:161-168. https:// doi.org/10.1016/S0141-3910(97)00196-1

40. Aghjeh MR, Kazerouni Y, Otadi M, Khonakdar HA, Jafari SH, Ebadi DH, Mousavi SH (2018) A combined experimental and theoretical approach to quantitative assessment of microstructure in PLA/PP/Organo-clay nanocomposites; wide-angle X-ray scattering and rheological analysis. Compos B Eng 137:235-246. https://doi.org/10.1016/j.compositesb.2017.10.036

41. Acioli-Moura R, Sun XS (2008) Thermal degradation and physical aging of poly(lactic acid) and its blends with starch. Polym Eng Sci 48:829-836. https://doi.org/10.1002/pen.21019

42. Zhang L, Xiong C, Deng X (1996) Miscibility, crystallization and morphology of poly( $\beta$-hydroxybutyrate)/poly(D, L-lactide) blends. Polymer 37:235-241. https://doi.org/10.1016/0032-3861(96) 81093-7

43. D'Anna A, Arrigo R, Frache A (2019) PLA/PHB blends: Biocompatibilizer effects. Polymers 11:1416. https://doi.org/10.3390/ polym 11091416

44. Long Y, Zhang R, Huang J, Wang J, Zhang J, Rayand N, Hu G-H, Yang J, Zhu J (2017) Retroreflection in binary bio-based PLA/ PBF blends. Polymer 125:138-143. https://doi.org/10.1016/j. polymer.2017.08.004

45. Poulopoulou N, Kasmi N, Siampani M, Terzopoulou ZN, Bikiaris DN, Achilias DS, Papageorgiou DG, Papageorgiou GZ (2019) Exploring next-generation engineering bioplastics: poly(alkylene furanoate)/poly(alkylene terephthalate) (PAF/PAT) blends. Polymers 11:556-571. https://doi.org/10.3390/polym11030556

46. Poulopoulou N, Kasmi N, Bikiaris DN, Papageorgiou DG, Floudas G, Papageorgiou GZ (2018) Sustainable polymers from renewable resources: polymer blends of furan-based polyesters.
Macromol Mater Eng 303:1800153. https://doi.org/10.1002/ mame.201800153

47. Long Y, Zhang RY, Huang JC, Wang JG, Jiang YH, Hu GH, Yang J, Zhu J (2017) Tensile property balanced and gas barrier improved poly(lactic acid) by blending with biobased poly(butylene 2,5-furan dicarboxylate). ACS Sustain Chem Eng 5:9244-9253. https://doi.org/10.1021/acssuschemeng.7b02196

48. Fredi G, Rigotti D, Bikiaris DN, Dorigato A (2021) Tuning thermo-mechanical properties of poly(lactic acid) films through blending with bioderived poly(alkylene furanoate)s with different alkyl chain length for sustainable packaging. Polymer 218:123527. https://doi.org/10.1016/j.polymer.2021.123527

49. Girijappa YGT, Rangappa SM, Siengchin S (2019) Natural fibers as sustainable and renewable resource for development of ecofriendly composites: a comprehensive review. Front Mater 6:226. https://doi.org/10.3389/fmats.2019.00226

50. Janaina AK, Miguel P, Davi B-G, Barrella W (2020) Textile sustainability: a Brazilian etiquette issue. Environ Sci Policy 109:125-130. https://doi.org/10.1016/j.envsci.2020.02.025

51. Mackley M (2002) Polymer processing: the physics of stretching chains. Phys Technol 9:13. https://doi.org/10.1088/0305-4624/9/ $1 / \mathrm{I} 03$

52. Codou A, Guigo N, van Berkel JG, de Jong E, Sbirrazzuoli N (2017) Preparation and characterization of poly(ethylene 2,5-furandicarboxylate/nanocrystalline cellulose composites via solvent casting. J Polym Eng. https://doi.org/10.1080/00914037. 2014.977897

53. Sato S, Gondo D, Wada T, Kanehashi S, Nagai K (2013) Effects of various liquid organic solvents on solvent-induced crystallization of amorphous poly(lactic acid) film. J Appl Polym Sci 129:1607-1617. https://doi.org/10.1002/app.38833

54. Jamshidi K, Hyon SH, Ikada Y (1988) Thermal characterization of polylactides. Polymer 29:2229-2234. https://doi.org/10.1016/ 0032-3861(88)90116-4

55. Gupta B, Revagade N, Anjum N, Atthoff B, Hilborn J (2006) Preparation of poly(lactic acid) fiber by dry-jet-wet-spinning. I. Influence of draw ratio on fiber properties. J Appl Polym Sci 100:1239-1246. https://doi.org/10.1002/app.23497

56. Dabrowska I, Fambri L, Pegoretti A, Slouf M, Vackova T, Kolarik J (2015) Spinning, drawing and physical properties of polypropylene nanocomposite fibers with fumed nanosilica. Express Polym Lett 9:277-290. https://doi.org/10.3144/expresspolymlett.2015.25

57. Fredi G, Bruenig H, Vogel R, Scheffler C (2019) Melt-spun polypropylene filaments containing paraffin microcapsules for multifunctional hybrid yarns and smart thermoregulating thermoplastic composites. Express Polym Lett 13:1071-1087. https://doi.org/10. 3144/expresspolymlett.2019.93

58. Davachi SM, Kaffashi B (2015) Preparation and characterization of poly L-lactide/triclosan nanoparticles for specific antibacterial and medical applications. Int J Polym Mater Polym Biomater 64:497-508. https://doi.org/10.1080/00914037.2014.977897

59. Goh PS, Ismail AF (2020) Chapter 4-nanocomposite membrane fabrication. Nanocomposite membranes for gas separation, vol 125-162. Elsevier, Amsterdam

60. Hamanaka S, Yamashita K, Nonomura C, Thi TBN, Wakano T, Yokoyama A (2017) Measurement of fiber orientation distribution in injection-molded composites with high filler content. AIP Conf Proc 1914:140011. https://doi.org/10.1063/1.5016776

61. Terzopoulou Z, Tsanaktsis V, Nerantzaki M, Achilias DS, Vaimakis T, Papageorgiou GZ, Bikiaris DN (2016) Thermal degradation of biobased polyesters: kinetics and decomposition mechanism of polyesters from 2,5-furandicarboxylic acid and long-chain aliphatic diols. J Anal Appl Pyrol 117:162-175. https://doi.org/10. 1016/j.jaap.2015.11.016

62. Lim LT, Auras R, Rubino M (2008) Development of biobased poly(lactic acid)/epoxidized natural rubber blends processed by 
electrospinning: morphological, structural and thermal properties. Mater Sci Appl 7:820-852. https://doi.org/10.4236/msa.2016. 74021

63. Jompang L, Thumsorn S, On JW, Surin P, Apawet C, Chaichalermwong T, Kaabbuathong N, Oharoen N, Srisawat N (2013) Poly(lactic acid) and poly(butylene succinate) blend fibers prepared by melt spinning technique. Energy Procedia 34:493-499. https://doi.org/10.1016/j.egypro.2013.06.777

64. Essabir H, El Mechtali FZ, Nekhlaoui S, Raji M, Bensalah MO, Rodrigue D, Bouhfid R, Qaiss A (2020) Compatibilization of PA6/ABS blend by SEBS-g-Ma: morphological, mechanical, thermal, and rheological properties. Int J Adv Manuf Technol 110:1095-1111. https://doi.org/10.1007/s00170-020-05888-5

65. Wang F, Liu L, Xue P, Mingyin J (2017) Crystal structure evolution of UHMWPE/HDPE blend fibers prepared by melt spinning. Polymers 9:96. https://doi.org/10.3390/polym9030096

66. Li L, Huang W, Wang $\mathrm{B}$, Wei $\mathrm{W}, \mathrm{Gu} \mathrm{Q}$, Chen $\mathrm{P}$ (2015) Properties and structure of polylactide/poly (3-hydroxybutyrate-co-3-hydroxyvalerate) (PLA/PHBV) blend fibers. Polymer 68:183-194. https://doi.org/10.1016/j.polymer. 2015.05.024

67. La Mantia FP, D’Amico R, Acierno D (1979) Uniaxial hot stretching of polystyrene and mechanical properties of the oriented samples. Acta Polym 30:685-688. https://doi.org/10.1002/actp.1979. 010301104

68. La Mantia FP, Fontana P, Morreale M, Mistretta MC (2014) Orientation induced brittle-ductile transition in a polyethylene/ polyamide 6 blend. Polym Testing 36:20-23. https://doi.org/10. 1016/j.polymertesting.2014.03.009

Publisher's Note Springer Nature remains neutral with regard to jurisdictional claims in published maps and institutional affiliations. 